\title{
Abordagem familiar e projeto terapêutico singular na estratégia saúde da família: estudo de caso com idosos
}

\section{Family approach and individualized therapeutic projects in Family Health Strategy: a case study with elderly patients \\ Abordaje familiar y proyecto terapéutico singular en la estrategia salud de la familia: estudio de caso con ancianos}

\section{Recebido: 19/06/2018 Aprovado: 12/11/2018 Publicado: 29/01/2019}

Ana Luisa Nunes Marques ${ }^{1}$ Fernanda Carolina Camargo ${ }^{2}$ Joyce Mara Gabriel Duarte ${ }^{3}$ Ana Jecely Alves Pereira Lima ${ }^{4}$ Francielle Thaisa Morais Martins ${ }^{5}$ Hayanny Pires Netto Guimarães ${ }^{6}$ Luana Rodrigues Rosseto Felipe ${ }^{7}$ Matheus Marques e Marques ${ }^{8}$ Simone Almeida dos Santos ${ }^{9}$

Trata-se de estudo de caso único, descritivo-narrativo, orientado pelo Modelo Calgary de Avaliação Familiar que teve como objetivo analisar a implementação da abordagem familiar na estratégia saúde da família e elaboração do projeto terapêutico singular. Foram realizadas visitas domiciliares; entrevistados seis agentes comunitários de saúde e analisados indicadores da equipe - entre junho e agosto/2017. 0 caso analisado foi composto por uma família de idosos que cuidam de idosos. Evidenciou-se duas categorias: "O Contexto sócio epidemiológico do território" e "A Família e o Projeto Terapêutico Singular". Apresentou-se: higiene pessoal e limpeza da casa precárias, dificuldades no manejo do regime medicamentoso, vínculos frágeis e conflituosos com a família estendida, ausência de integração em atividades comunitárias. Construções compartilhadas em equipe orientaram a elaboração do Projeto Terapêutico Singular. Conferência familiar, diálogos que geraram compromissos, painel com atividades domésticas, integração ao grupo comunitário de ginásticas e estreitamento de vínculos com equipe de saúde compuseram intervenções. Conclui-se que o caso relatado contribui para orientar o trabalho interprofissional com famílias para produção de cuidados na atenção básica. Descritores: Estratégia Saúde da Família; Internato e Residência; Relações familiares; Envelhecimento.

It is a descriptive-narrative case study, guided by the Calgary model of family evaluation, and its aim was analyzing the implementation of the family approach in the family health strategy and the elaboration of the individualized therapeutic project. Home visits were carried out; six Community Health agents were interviewed and the indicators of the team, between June and August 2017, were analyzed. The case examined was that of a family of elderly people who care for other elders. Two categories were found: "the socio-epidemiological context of the territory" and "the family and the individualized therapeutic project". Were found: precarious personal hygiene and house cleaning, difficulties in the management of the drugs, fragile and conflictual ties with the extended family, lack of integration in community activities. Shared collective constructions guided the elaboration of the individualized therapeutic project. Family reunions, dialogues that generated commitment, panel with domestic activities, integration with the community group of gymnastic and bond creation with the health team were the discussed interventions. It was concluded that the reported case contributes to orienting inter-professional work with families for the provision of care in the Primary health care.

Descriptors: Family Health Strategy; Internship and Residency; Family relations; Aging.

Se trata de un estudio de caso único, descriptivo-narrativo, orientado por el Modelo Calgary de Evaluación Familiar que tuvo como objetivo analizar la implementación del abordaje familiar en la estrategia salud de la familia y elaboración del proyecto terapéutico singular. Fueron realizadas visitas domiciliarias; entrevistados seis agentes comunitarios de salud y analizados indicadores del equipo - entre junio a agosto de 2017. El caso analizado fue compuesto por una familia de ancianos que cuidan a ancianos. Se evidenciaron dos categorías: "El contexto socio-epidemiológico del territorio" y "La Familia y el Proyecto Terapéutico Singular". Se presentó: higiene personal y limpieza de casas precarias, dificultades en el manejo del régimen medicamentoso, vínculos frágiles y conflictivos con la familia extendida, ausencia de integración en actividades comunitarias. Construcciones compartidas en equipo orientaron la elaboración del Proyecto Terapéutico Singular. Conferencia familiar, diálogos que generaron compromisos, panel con actividades domésticas, integración al grupo comunitario de gimnásticas y estrechamiento de vínculos con el equipo de salud, compusieron intervenciones. Se concluye que el caso relatado contribuye para orientar el trabajo interprofesional con familias para la producción de cuidados en la atención básica.

Descriptores: Estrategia de Salud Familiar; Internado y Residencia; Relaciones familiares; Envejecimiento.

1. Enfermeira. Especializanda na modalidade Residência Integrada Multiprofissional em Saúde (RIMS) do Idoso pela Universidade Federal Triângulo Mineiro (UFTM), Uberaba, MG, Brasil. ORCID: 0000-0003-3328-2537 E-mail: anawisanunes@hotmail.com

2. Enfermeira. Mestre e Doutora em Atenção à Saúde. Tutora da Especialização em Saúde da Família do Núcleo de Educação em Saúde Coletiva da Universidade Federal de Minas Gerais. Epidemiologista Clínica do Setor de Pesquisa e Inovação Tecnológica do Hospital de Clínicas da UFTM. Analista de Regulação em Saúde da Secretaria Municipal de Saúde de Uberaba, MG, Brasil. ORCID: 0000-0002-1048-960X E-mail: fernandaccamargo@yahoo.com.br

3. Enfermeira. Especialista em Docência da Educação Superior. Mestre e Doutora em Atenção à Saúde. Tutora da RIMS/UFTM, Uberaba, MG, Brasil. ORCID: 0000-0002-4501-9712 E-mail: joyceduarte@hotmail.com

4. Assistente Social. Especializanda em Saúde do Idoso na modalidade RIMS/UFTM, Uberaba, MG, Brasil. ORCID: 0000-0001-7959-1437 E-mail: AninhaJecely@hotmail.com

5. Fisioterapeuta. Especializanda em Saúde do Idoso na modalidade RIMS/UFTM, Uberaba, MG, Brasil. ORCID: 0000-0002-9149-6042 E-mail: fran_thaisa@hotmail.com

6. Nutricionista. Especialista em Saúde do Idoso, Uberaba, MG, Brasil. ORCID: 0000-0003-1306-4428 E-mail: hayanny22@hotmail.com

7. Fisioterapeuta. Especialista em Saúde do idoso. Mestranda do Programa de Pós-Graduação em Fisioterapia da UFTM, Uberaba, MG, Brasil. ORCID: 0000-0003-3892-6936 E-mail: luanafisioterapiauftm@gmail.com

8. Fisioterapeuta. Especialista em Saúde do idoso. Mestrando do Programa de Pós-Graduação em Educação Física da UFTM, Uberaba, MG, Brasil. ORCID: 0000-0002-6959-1473 E-mail: matheusmarquesemarques@live.com

9. Enfermeira. Especializanda em Saúde do Idoso na modalidade RIMS/UFTM, Uberaba, MG, Brasil. ORCID: 0000-0001-8694-8203 E-mail: simoonealmeida@hotmail.com 


\section{INTRODUÇÃO}

A tenção Básica à Saúde (ABS) compõe ações do primeiro nível de saúde nos sistemas locais (municipais). E deve estar vinculada à rede de serviços de forma que garanta a efetivação dos princípios norteadores do Sistema Único de Saúde (SUS) ${ }^{1,2}$.

Após mais de 20 anos de instituído o SUS, alguns desafios emergem no cenário nacional para sua efetivação, em especial naquilo que tange a ordenação da ABS para que seja transformadora de forma positiva ao sistema. Os desafios configuram a ineficiência do setor público no provimento $\mathrm{e}$ financiamento das ações, a necessidade de ampliação da satisfação da população e a garantia da qualidade dos serviços prestados frente a existência de iniquidades. Outro aspecto a ser superado para a efetividade desse sistema constitui-se na organização de ações, para além de um modelo procedimento-centrado, mediante a perspectiva médico-hegemônica ${ }^{1-3}$.

Como resposta, em 1994, o Ministério da Saúde, a partir de experiências bemsucedidas em municípios da região Nordeste - pelos Agentes Comunitários de Saúde - e da cidade de Campinas - por ações de promoção da saúde - lança o Programa Saúde da Família. Sendo que em 2011, reformula esse programa na Política Nacional de Atenção Básica - mencionando-o como uma Estratégia para o fortalecimento do nível primário de atenção e reordenação do modelo tecnoassistencial em saúde vigente ${ }^{2}$.

Em especial, a regulamentação da ABS em 2011 emerge, porque neste contexto, o SUS busca sua organização regionalizada e normatizada em Redes de Atenção à Saúde, para garantir a composição de serviços de diferentes complexidades com mais alto grau de resolutividade e acesso oportuno para resguardar as vidas. Em setembro de 2017, por meio da portaria 2436, foi estabelecida a revisão de diretrizes para a ABS. Sendo discutido o reconhecimento de outros formatos de equipe, a inclusão do gerente de atenção básica, como componente da equipe, a redução da população adstrita, garantia da continuidade do uso do sistema de informação em saúde por módulos otimizados ${ }^{2,4}$.

Sobretudo, pretende-se na ABS orientada pela Estratégia Saúde da Família (ESF) que a assistência esteja ancorada em um processo de trabalho promotor de cuidado ampliado em saúde, sendo a família (as relações dinâmicas entre os indivíduos em sua composição) em seu contexto territorial (aqui território entendido como processo vivo epidemiológico e sociocultural) - a unidade a ser abordada1,3.

Para tanto, as equipes de saúde devem organizar seu trabalho estabelecendo vínculos com o território vivo. A atuação na ABS/ESF deve prescindir de tecnologias de cuidado complexas e variadas, orientadas por critérios de risco e vulnerabilidades de indivíduos, famílias e comunidades em seus territórios ${ }^{1-4}$.

Para o campo da saúde, no Brasil, onde o estado de bem-estar social ainda não foi efetivado em sua plena acepção, a família ocupa papel central na provisão do bemestar, especialmente após os anos (com o envelhecer), entretanto, as concepções governamentais de família têm sido controversas, tencionando interesses e discursos de diversas ordens ${ }^{5,6}$.

Como consequência, discute-se até que ponto a política tem sido capaz de abarcar toda a diversificação de formas familiares existentes, ou privilegia um modelo de família determinado, deixando outros a margem. Por sua vez, ainda são escassas no Brasil publicações que utilizem da abordagem familiar, mesmo ela sendo orientadora da atuação na ABS/ESF5,6.

Isto pois, apesar de ser consistente entre os profissionais de saúde a concepção de que as condições familiares interferem no processo saúde-doença, faltam estudos sobre o trabalho dos profissionais da ABS/ESF com famílias, de modo a evidenciar como se verifica na prática cotidiana desses profissionais a abordagem familiar ${ }^{5-7}$.

Neste âmbito, a família constitui-se como a microestrutura que mais peso teria na constituição das representações e práticas dos sujeitos em relação ao processo saúdedoença-cuidado. Sendo o âmbito familiar 
uma referência chave nas determinações da morbimortalidade em diferentes grupos etários, nas dimensões importantes da estrutura sociocultural, como as relações de gênero ou posição social, como os valores, condutas sociais e padrões de mobilização. Por essa razão, confere-se à família a condição de unidade de análise estratégica para investigação de tal processo ${ }^{7}$.

Diante desta realidade questiona-se: como implementar a abordagem familiar no cenário da ABS/ESF? Nesta perspectiva, este estudo teve como objetivo analisar a implementação da abordagem familiar na estratégia saúde da família e a elaboração do projeto terapêutico singular.

\section{MÉTODO}

Trata-se de um estudo desenvolvido na perspectiva do estudo de caso comparado descritivo. 0 método de estudo de caso propõe examinar acontecimentos contemporâneos, relacionados a fenômenos sociais complexos. Conta com técnicas usualmente utilizadas, tais como observação direta, série sistemática de entrevista e análise de dados propícios a responder questões de estudos que permeiam o "como" ou o "por que" de determinado fenômeno 8 .

Assim, há de se atentar para o fato de que o locus do estudo não é o objeto, em si. Ao invés da limitação a priori do caso, a abordagem do estudo de caso comparado apresenta acompanhamentos interativos entre um contingente de fatores, atores e características relevantes para a compreensão do fenômeno. Enxergar o fenômeno em termos de pessoas, situações, eventos e os processos que os conectam ${ }^{8}$.

Em junho de 2016, em termo de parceria firmado entre a Secretaria Municipal de Saúde de Uberaba/Minas Gerais e o Hospital de Clínicas da Universidade Federal do Triângulo Mineiro (UFTM) foi prevista a instauração de cenário de inserção de práticas com ênfase na ABS/ESF para estudantes do nível técnico, licenciatura, graduação e pós-graduação da UFTM, por uma unidade caracterizada como centro de saúde escola - Centro de Atenção Integrada à Saúde (CAIS), com vistas a promover o desenvolvimento de projetos de ensino, extensão, pesquisa e inovação tecnológica, para com isso assegurar o papel da universidade, coadunada ao hospital, de retorno à sociedade por parte de suas atividades.

Trata-se de um novo espaço para a integração ensino-serviço, composto por uma unidade de apoio a seis equipes de saúde da família, com uma abrangência territorial de cobertura a aproximadamente 5.600 famílias, em diferentes condições de vulnerabilidade socioepidemiológicas.

O projeto operacional do CAIS incorpora políticas contemporâneas para formação na perspectiva da Promoção à Saúde, centralidade na atenção básica e reordenação do modelo pela Estratégia Saúde da Família, considerando atuação em rede integrada à saúde pelo fortalecimento da alta hospitalar qualificada e cuidado contínuo longitudinal.

0 contexto do caso abordado partiu da experiência de atuação na área de concentração Saúde do Idoso do Programa de Pós-Graduação lato sensu Residência Integrada Multiprofissional em Saúde (RIMS) do Hospital de Clínicas da UFTM, junto ao CAIS.

Esse programa de residência multiprofissional teve início em 2010, com a proposta de formar profissionais: assistentes sociais, enfermeiros, terapeutas ocupacionais, fisioterapeutas, nutricionistas, psicólogos, biomédicos e profissionais da educação física.

A RIMS considera, em seu projeto político pedagógico, a promoção de atributos que possibilitem o exercício profissional com excelência nas áreas de cuidado integral e humanizado em saúde, envolvendo as pessoas e as comunidades, a gestão e organização do trabalho de educação em saúde, visando a melhoria da qualidade de vida.

Como proposta de referencial metodológico foi empreendido o estudo de um caso único incorporado por unidades múltiplas de análise, sendo: a família acompanhada pelos residentes da RIMS. E, as subunidades de análise relacionaram-se à 
caracterização do contexto familiar e ao projeto terapêutico elaborado frente à abordagem familiar.

Seguiu-se o Modelo Calgary de Avaliação familiar', que permite avaliar a família numa perspectiva multidimensional e ecossistêmica, considerando as dimensões de avaliação: a estrutura familiar, e o desenvolvimento familiar e a sua funcionalidade, sendo este modelo $o$ referencial teórico-metodológico adotado.

Neste modelo a família é compreendida de forma sistêmica, sendo a unidade familiar um continuum retroalimentado entre estabilidade $\mathrm{e}$ mudança, o qual permite transformações na sua estrutura, mantendo a sua organização e, conferindo desenvolvimento próprio como uma sequência natural ao longo do seu ciclo de vida. A adoção deste modelo é indicada como benéfica para a promoção da interação com as famílias e um melhor planejamento dos cuidados 9 .

Para a composição do estudo de caso comparado, as entrevistas por meio das visitas foram organizadas conforme orientado pelo Modelo Calgary de Avaliação familiar com o intuito de gerar engajamento - construção de vínculos junto à família; avaliação familiar em si - para exploração e identificação de demandas em saúde. A intervenção: construção do Projeto Terapêutico Singular (PTS) com plano de cuidados por meio de discussão coletiva dos residentes e preceptora do programa (profissional com especialização em famílias e experiência prática na abordagem familiar).

0 PTS é concebido por uma perspectiva plural de saberes válidos e normatividades de natureza não tecnicista ${ }^{10}$. Implica a adoção da cooperação entre os atores imersos no contexto.

Como meio estratégico, abre-se um caminho para uma interpretação menos presa a uma racionalidade tecnicista, frente à possibilidade de elaboração de um projeto solidário - PTS - entendido como desafio permanente da interação horizontalizada entre equipe de saúde e a autonomia das famílias assistidas ${ }^{10}$.
A família abordada foi incluída no estudo por identificação a partir da demanda apresentada aos residentes por uma das equipes de saúde de abrangência do centro de saúde escola, tida como uma família de "difícil" manejo pela sua equipe de saúde da família de referência. A coleta de dados foi realizada por residentes da RIMS, por meio de entrevistas no domicílio e área onde a família reside, juntamente com a Agente Comunitária de Saúde responsável. Foram realizadas cinco visitas domiciliares, com duração de aproximadamente 60 a 90 minutos, de junho a agosto de 2017. As entrevistas foram registradas em caderno de campo. Os resultados foram apresentados de forma discursiva-narrativa, frente a descrição do caso.

Ainda, foram incorporadas como unidade de análise entrevistas abertas junto aos seis agentes comunitários de saúde (ACS) da ESF de referência da unidade familiar, para compreensão do contexto sócio territorial.

Foram questionados de forma livre o modo de levar a vida daquela comunidade e as respostas foram registradas no caderno de campo do entrevistador, sendo essa coleta em momento único, durante a reunião de educação continuada da equipe de saúde previamente pactuada a realização junto ao enfermeiro responsável. Ocorreu em julho/2017 com duração de 120 minutos. Os resultados foram apresentados de forma discursiva-narrativa, conforme a leitura dos registros.

Foram utilizados dados secundários do sistema de informação da atenção básica (e-SUS/SIAB) da equipe de saúde da família de referência da unidade de análise, sobre indicadores que caracterizaram o território e seus aspectos sociossanitários.

Utilizou-se os dados mais recentes disponíveis nesses sistemas, com intuito de se retratar a realidade sanitária do contexto de inserção da família abordada. Esses indicadores são produzidos no cotidiano de trabalho da equipe de saúde da família e descrevem as características da área de abrangência de sua responsabilidade, conforme dados do perfil sociodemográfico e 
epidemiológico. Esses resultados foram apresentados conforme frequência absoluta e relativa, como um breve diagnóstico situacional.

Quanto aos aspectos éticos, os nomes dos integrantes da família foram substituídos por nomes fictícios para minimizar constrangimentos quanto à exposição. Foi respeitada a resolução CNS 466/2012, e recebida aprovação do Comitê de Ética em Pesquisa da Universidade Federal do Triângulo Mineiro, em 2017, sob o parecer nํㅡㅁ 2.427.323. Os dados foram coletados após assinatura do Termo de Consentimento Livre Esclarecido pelos participantes.

\section{RESULTADOS}

Conforme o protocolo para desenvolvimento do estudo de caso, os resultados serão apresentados como "O Contexto socioepidemiológico do território" e "A Família e o Projeto Terapêutico Singular"

\section{o Contexto socioepidemiológico do território}

O território de inserção da família abordada caracteriza-se por ser área de abrangência de ESF vinculada ao CAIS. A área de abrangência da ESF possui 3.555 pessoas cadastradas, sendo 1002 famílias. Quanto ao perfil demográfico, $52,9 \%$ da população é do sexo feminino e $47,1 \%$ do sexo masculino. Quanto à população idosa, que possui mais de 60 anos, soma $25 \%$ dos moradores.

De acordo com o relatório consolidado do Sistema de Informação da Atenção Básica de 2016, pode ser observado que as doenças mais prevalentes na área são Hipertensão Arterial, em 20,5\% dos habitantes, e Diabetes Mellitus em 6,7\%. Nota-se uma pequena quantidade de crianças na área, e apenas $0,96 \%$ das mulheres estão gestantes. Das crianças de 7 a 14 anos, 76,3\% frequentam a escola, 93,9\% dos moradores com 15 anos ou mais são alfabetizados. Entre as famílias, $25,5 \%$ das cadastradas possuem cobertura por planos de saúde, e apenas $0,6 \%$ recebem auxílio do bolsa família.

Quanto à estrutura física da área, 80,1\% das casas possuem tratamento da água em domicílio e 19,7\% não possuem tratamento de água. 0 abastecimento de água é realizado pela rede pública em $99,6 \%$ das casas. Todas as casas são de tijolo e 99,5\% possuem energia elétrica. 0 lixo é destinado pela coleta pública e $99,9 \%$ das casas possuem rede de esgoto.

$\mathrm{Na}$ entrevista com os ACS, os informantes chave do bairro, foi referido que a equipe é composta por seis agentes comunitárias de saúde, um médico, uma enfermeira, uma técnica de enfermagem e um auxiliar de saúde bucal.

Segundo dados da entrevista sobre a situação geral do bairro, relatou-se expressiva quantidade de idosos moradores. Os principais problemas de saúde referidos foram a hipertensão arterial sistêmica, o diabetes mellitus e a depressão. Informou-se não apresentar moradores em risco social. Sobre a sinalização das ruas, segundo os dados, é precária, porém, apresenta pavimentação regular. Não existem muitos terrenos baldios na região. 0 conselho local de saúde está inativo por não ter representantes.

As ACS referiram não haver pontos para lazer da comunidade, apenas uma praça pequena e ruim e o forró no Centro Social Urbano com entrada gratuita às quintasfeiras. Ainda, referiram muitos pontos de tráfico de drogas na região, sendo um dos pontos de encontro os bares. Observaram residir poucos pacientes acamados.

Relataram que a maior parte da população refere ter como prática religiosa o catolicismo, existindo na área de abrangência uma igreja católica. Há um elevado número de idosos que frequentam a paróquia, mas há a participação das pessoas de todas as faixas etárias, sendo frequentadores assíduos.

Porém, há maior número de igrejas evangélicas e centros espíritas. De forma geral, a comunidade religiosa, independentemente do tipo de prática religiosa exercida, realiza atividades assistenciais para a população mais pobre da área de abrangência, como doações de agasalhos e cestas básicas.

Como outros equipamentos sociais, a área de abrangência apresenta um único supermercado e apenas uma farmácia. Durante a entrevista foi possível perceber 
que o bairro se apresenta com elevada insegurança, por estarem os moradores expostos a situações de violência urbana como assaltos e tráfico de drogas - segundo relatado pelas ACS.

Frente aos resultados, como o diagnóstico situacional demonstrou, no bairro encontram-se mais idosos aposentados, e essa realidade se reflete na família abordada no caso. Quando se aproxima da situação do bairro onde a família está inserida, ou seja, do macrocontexto, tem-se mais subsídios para abordar o microcontexto familiar a partir da real necessidade e/ou demanda dos membros dessa família, através de um agir comunicativo e compreensivo.

Na primeira visita, realizada no dia 06 de junho de 2017, foram até o domicílio: Assistente Social, Enfermeira, Nutricionista e Fisioterapeuta - integrantes da RIMS. A família é composta por Rosa, Cravo, Margarida e Lírio.

Rosa e Cravo são casados e primos de primeiro grau, Rosa tem 67 anos e é do lar. Cravo tem 76 anos e é aposentado. 0 casal teve quatro filhos: dois faleceram, e Margarida, do sexo feminino, tem 43 anos, recebe benefício por uma deficiência intelectual, e mora junto com os pais. Antúrio é o outro filho, do sexo masculino, tem 50 anos, é pedreiro e mora no fundo da casa dos pais junto com suas filhas, netas do casal, Violeta de 21 anos e Orquídea de 19 anos. Também moram junto com o casal, o irmão de Cravo, Lírio, que tem 52 anos e trabalha como servente de pedreiro.

Ao chegar na casa da família, as ACS foram recebidas pela filha Margarida. Ao entrar na residência percebeu-se condições precárias de higiene. A casa possui 3 quartos, sala, cozinha, banheiro, garagem e um quintal com galinhas. Lírio trabalha e não estava presente durante a visita.

Rosa e Cravo estavam deitados na cama com limitações para deambular, foram questionados quanto a esse cenário, e alegaram que tinham dificuldades para andar e não se sentiam motivados a transitar pela casa. Os dois também estavam utilizando fraldas descartáveis e relataram que urinavam em vasilhas durante o dia. Foram encontradas várias vasilhas com urina $\mathrm{e}$ restos de alimentos pelos quartos.

Por conta dessas limitações, Cravo relatou que quem fica responsável pelo recebimento das aposentadorias dele e de Margarida é a sobrinha Íris, de confiança dele, que repassa todo o dinheiro mensalmente. Violeta, uma das netas que mora na casa do fundo, fica responsável pela compra de alimentos realizada também mensalmente.

0 irmão Lírio fica encarregado da limpeza da casa, preparar as refeições, e Margarida por dar os medicamentos para os pais. Quando as ACS questionaram sobre as medicações que os integrantes da casa ingeriam, notou-se que ambos não as tomavam corretamente e não entendiam a finalidade de cada medicação.

Durante a visita, foi perguntado para Margarida, em local separado, sobre a relação dela com os pais, já que se notou que o pai Cravo em certos momentos era grosseiro com ela. Porém a mesma relatou ter uma boa relação com os pais e inicialmente não foram evidenciados sinais de maus tratos. Foi perguntado a Cravo se a condição de higiene da casa o incomodava e o mesmo alegou não se importar com essa questão.

Durante a conversa com Cravo, observou-se que ele utilizava andador e/ou bengala como dispositivo auxiliar para deambular, e o mesmo relatou uma queda quando saiu de casa para dar uma volta no quarteirão e como consequência estava com lesão na face e nos pés. Cravo também se queixou de dor e da preocupação com a filha quando ele morrer, de quem irá repassar o benefício para Margarida. Cravo referiu ter vontade de fazer uma procuração para que a sobrinha pudesse continuar recebendo o dinheiro e repassando para Margarida.

A segunda visita foi realizada no dia 20 de junho de 2017 com o restante da equipe: Assistente Social, Enfermeira, Nutricionista e Fisioterapeutas. Foram recebidos pela filha Margarida e permaneceram na sala com Cravo. Durante a visita, notou-se que Cravo ainda estava preocupado com a questão da aposentadoria dele e de Margarida. Nesse 
momento, dialogaram sobre a questão da morte, e da preocupação do mesmo em assinar ou não a procuração que já estava pronta, para a sobrinha repassar o dinheiro para Margarida após a morte de Cravo. Após longo período de discussão, Cravo também relatou falta de força nos membros inferiores. Os Fisioterapeutas da equipe ensinaram para Cravo alguns exercícios para o fortalecimento dos membros para que ele realizasse em casa.

No segundo momento foi realizado o acolhimento de Rosa. Percebeu-se que a mesma permanece muito tempo no quarto deitada na cama, e que ela faz todas as necessidades e atividades de vida diária dentro desse cômodo, por exemplo: escovar os dentes, refeições, necessidades fisiológicas, e outras, e acumula todos os objetos e alimentos dentro do quarto. Percebeu-se também que toda a casa tem um odor desagradável, devido às condições deficientes de higiene. Durante a visita, uma das netas saiu da casa dos fundos, porém não manteve nenhum contato com os avós ou membros da equipe.

A visita foi encerrada, e os pesquisadores encontraram-se com todos os membros da equipe para discutir o caso. As ações foram pensadas e refletidas a partir da construção do conhecimento tendo como base a realidade vivenciada e problematizada por meio de discussões e supervisão direta de professores e especialistas no contexto da RIMS. Construções compartilhadas em equipe orientaram a elaboração do Projeto Terapêutico Singular.

\section{A família e o projeto terapêutico singular}

Inicialmente tentou-se contato com uma das netas, mas não houve sucesso. Foi realizada então a terceira visita dia 18 de julho de 2017 com todos os integrantes da equipe e uma das tutoras da RIMS. Ao chegar na casa a equipe foi recebida por Cravo, e toda a família reuniu-se na sala. Foi exposta à família, a partir de um diálogo franco e direto, a proposta conjunta da equipe e a necessidade de se estabelecer contratos de compromisso, numa perspectiva horizontal, respeitando as individualidades e singularidades dos sujeitos.
Importante salientar que tais compromissos não são engessados, cabendo ajustes e redefinições, tendo como principal direção as necessidades apresentadas pela família. Eles se mostraram muito receptivos às propostas.

Foram adotadas como estratégia para atendimento: as conferências em família, priorizando o diálogo conjunto para maior alinhamento das ações planejadas. Entendese que tais reuniões possibilitam 0 estabelecimento de propostas numa perspectiva conjunta, em um diálogo horizontal entre família e equipe, possibilitando a expressão de sentimentos, angústias, e de possibilidades de aceitação de compromissos previamente discutidos e propostos.

A princípio colocou-se como de extrema importância a organização, limpeza e higiene da casa e perguntou-se sobre a questão financeira da família. Foram instruídos quanto à retirada do lixo, de restos de alimentos, e quanto à organização da casa. A família também foi orientada quanto à importância de realizar todas as refeições na mesa da cozinha, e não nos quartos, como estava sendo feito.

Foram levadas caixas com divisórias para a organização dos medicamentos de que fazem uso, separou-se junto a eles as medicações de cada um corretamente, de acordo com a prescrição médica. Foi discutido com cada um como deveriam ser tomados os medicamentos.

Umas das ações estratégicas também realizadas no atendimento foi a identificação das relações existentes entre a família e os equipamentos sociais presentes no município e ações e políticas programáticas. Tal estratégia possibilitou maior conhecimento da realidade vivida pela família, bem como dos recursos sociais disponíveis.

Viabilizou-se acesso oportuno à rede de saúde por meio de referências ao próprio serviço da atenção básica, tendo em vista as diversas necessidades apresentadas pela família, no sentido de garantir a integralidade e o acesso efetivo à rede pública.

Ao considerar a questão física dessa família, ou seja, as limitações e as 
dificuldades para sair de casa ou até mesmo andar pela casa, analisou-se a importância do exercício físico para essa família. A partir disso foi feito um convite para que todos participassem da ginástica que a equipe oferecia no Centro Espírita localizado há quatro minutos da casa. No primeiro momento, Cravo gostou da ideia, porém pediu um tempo para se organizar.

Durante a quarta visita, realizada no dia 25 de julho de 2017 a equipe foi recebida por Margarida. Reuniu-se toda a família na sala, a casa estava mais organizada, mas as condições de higiene pessoal e dos quartos ainda estavam precárias. Rosa, Cravo e Margarida estavam com as roupas sujas, as camas estavam desorganizadas, com muitas coisas em cima e com lençóis sujos.

Foi feito um painel com as atividades domésticas mais simples, para que estabelecessem juntos as responsabilidades de cada integrante da família, relacionadas com a limpeza e organização da casa, sendo esta uma ideia bem aceita por todos.

A Assistente Social da equipe ligou para Íris, e perguntou se ela poderia estar presente na próxima visita. Ela foi até a casa da família como combinado, e durante a visita, reafirmou que a família recebe apenas dois salários mínimos, e que está articulando a aposentadoria do Lírio. 0 irmão Lírio segundo Íris, trabalha com reciclagem, e fica responsável por pagar a energia da casa, e segundo relatos dos dois, Lírio sofre maus tratos pela família.

Íris apenas retira o dinheiro do banco, paga o plano funerário e leva o restante para o Cravo. E referiu que não existe essa procuração, ela tem acesso apenas aos dados bancários e cartões, e que eles não têm condições de pagar uma faxineira e estão pagando Violeta, mas ela não vai todas as vezes. Íris tentou articular a aposentadoria da Rosa, porém Cravo fica desconfiado e não deixa os documentos durante muito tempo com ela, e sem os documentos ela não consegue dar andamento nos procedimentos. A casa não tem escritura, e Íris está tentando organizar os papeis relacionados a isso.

Outro ponto importante consiste no compartilhamento de experiências com a equipe de saúde da família de referência, para se discutir ações e estratégias e construir conhecimento conjunto e compartilhado, utilizando-se o momento destinado para a educação continuada da equipe. Além do compartilhamento de experiências, é possível dar visibilidade ao trabalho desenvolvido pelos residentes em um contexto de trabalho multiprofissional e interdisciplinar.

Ressalta-se que para todas as etapas houve supervisão especializada técnicocientífica, orientada por discussões junto a preceptoria especializada em abordagem familiar. Para garantir o alinhamento das ações e o aprofundamento teórico.

\section{DISCUSSÃO}

Em convergência à análise do caso estudado, tem sido apontado que a abordagem familiar permite a identificação de conflitos, percepção do processo de saúde e doença, da rede de suporte (recursos materiais e emocionais), além de viabilizar o reconhecimento das forças da família e dos pontos críticos a serem minimizados, por meio de planos de intervenção ${ }^{11,12}$.

Como no presente estudo de caso, tem sido comum, em produções nacionais, a utilização da abordagem familiar para avaliar o apoio da família a doentes crônicos; ou famílias com idosos que necessitam de cuidados aproximados. Discute-se a vivência de uma série de mudanças pessoais e familiares, salientando que dependendo da gravidade da doença é necessário que sejam feitas alterações na forma de viver da família11-14.

Outros estudos corroboram o presente quanto ao fato de que a família abordada foi indicada pela equipe da ESF por ser de difícil manejo ${ }^{11-17}$. As entrevistas para abordagem familiar têm sido motivadas por alguma informação relacionada à família fornecida por membros da equipe, indicativa de conflito interpessoal entre os membros da família ou entre família e equipe de saúde ${ }^{15-}$ 17.

Práticas como empreender a escuta reflexiva, o questionar e a dialogia são instrumentalizações que marcam o cotidiano 
de trabalho junto às famílias. 0 reconhecimento das necessidades ampliadas de saúde das famílias, o compromisso e o vínculo estimulam práticas mais integradas, marcadas pela intersetorialidade e interdisciplinaridade, sinalizando a potencialidade para reconfiguração do modelo de atenção, aproximando-se a integralidade do cuidado ${ }^{15,17,18}$.

De um modo geral, a experiência relatada buscou apresentar a implementação de iniciativas que ampliem o escopo do modelo biomédico hegemônico, no qual tem sido predominantes abordagens de prontaconsulta, limitadas à compreensão da doença orgânica, de modo que pouco são consideradas as relações sociofamiliares e do contexto territorial como condicionantes aos processos de adoecimento das populações ${ }^{11,18,19}$.

Sobretudo, investir em ações para a reversão do modelo hegemônico condiz com aproximar as práticas de saúde ao princípio da integralidade do cuidado no SUS ${ }^{11,19}$.

Haja vista que quanto à organização do trabalho cotidiano, pretende-se na Atenção Básica, orientada pela Estratégia Saúde da Família, que a assistência esteja ancorada em um processo de trabalho promotor de cuidado ampliado à saúde. A família, com suas relações dinâmicas entre os indivíduos em sua composição, em seu contexto territorial - aqui território entendido como processo vivo epidemiológico e sociocultural -, é a unidade a ser abordada ${ }^{11,19}$.

Em outro aspecto, sobre os resultados apresentados, é imprescindível que os profissionais de saúde compreendam questões que envolvam o envelhecimento, a funcionalidade familiar e o contexto social em que se inserem as pessoas idosas, para com isso alcançarem estratégias de cuidado adequadas $^{19-22}$.

Durante o processo de envelhecimento, as famílias sofrem mudanças, deparam-se com diferentes situações que podem afetar a funcionalidade familiar, e acarretar impactos na harmonia e no equilíbrio existentes nessa relação, traduzindo-se em desafios tanto na composição familiar quanto ao trabalho da equipe de saúde 20,21 .

Como meio estratégico, abre-se um caminho para uma interpretação menos presa a uma racionalidade tecnicista na produção de cuidados em saúde, frente a possibilidade de elaboração de um projeto solidário - projeto terapêutico singular, entendido como desafio permanente da interação horizontalizada entre equipe de saúde e a autonomia das famílias assistidas $^{15,17,18 .}$.

0 estudo apresenta a necessidade em compreender a abordagem familiar em famílias envelhecendo como um processo que deve envolver os próprios indivíduos, a unidade familiar e a sociedade. Nesta perspectiva, a dimensão sistêmica do cuidado, propiciada pelo referencial teórico empregado, possibilitou o reconhecimento de condições de estrutura e contexto do próprio território, que poderiam apoiá-los na superação de suas necessidades ${ }^{19-22}$.

Nesse sentido, vale ressaltar o comprometimento da equipe multiprofissional para buscar o cuidado integral, envolver todos os participantes no ato de cuidar, incluindo necessariamente os idosos, a família cuidadora, a equipe de saúde e recursos comunitários, em arranjos viabilizadores de um microssistema de proteção ${ }^{19-22}$.

Quanto à construção do PTS, pode-se pontuar a importância dos encontros sistematizados entre o grupo de residentes para se alinhar as ações. Sabe-se que muitas vezes os profissionais de saúde se veem imersos em uma rotina de trabalho que faz com que eles não percebam a importância de dedicar tempo para refletir e discutir as ações em equipe ${ }^{23}$.

Esses encontros devem ser valorizados para que a equipe atue na elaboração de sentidos ao trabalho proposto mediante a revisão crítica do próprio trabalho. Composição essa - a reflexão crítica essencial à elaboração de PTS, a qual permeia a problematização da prática em saúde para se alcançar a gestão do cuidado ${ }^{23,24}$.

De acordo com o presente caso relatado, a utilização de iniciativas como o 
acompanhamento semanal da família implica no estreitamento de laços. Sendo a construção de vínculos entre família e equipe um fato que possibilita o alcance de êxito nas ações propostas pelo PTS, haja vista que a construção de vínculo promove o reconhecimento das singularidades existentes na família atendida. E o reconhecimento da singularidade dos indivíduos e coletivos junto ao emprego de tecnologias leves em saúde compõe dimensões do PTS 23,24 .

A preceptoria especializada propiciou a discussão conjunta e o desenvolvimento de estratégias para a construção do PTS, como aprofundamento teórico no tema pelo grupo de residentes, o que viabilizou maior potencial para o compartilhamento de experiências com a equipe de saúde da família de referência - o sentido de gerar troca de saberes.

A limitação do estudo relaciona-se à metodologia empreendida, pois os estudos de caso são generalizáveis a proposições teóricas, e não a populações ou universos. São generalizações analíticas. De maneira que o estudo de caso visa estabelecer ou esclarecer um conjunto de decisões frente ao motivo pelo qual foram adotadas, como foram implementadas e com quais resultados.

Porém, o presente estudo de caso é potencial e contribui ao incremento da produção científica para evidenciar como tem sido na prática cotidiana da ABS/ESF a aplicação da abordagem familiar. Podendo o método analítico ser reproduzido em contextos similares.

\section{CONCLUSÃO}

O caso apresentado ganha destaque ao relatar uma abordagem frente à situação de disfunção familiar de uma família de idosos responsáveis pelo cuidado entre si - uma família de idosos que cuidam de idosos.

Frente aos desafios para o cuidado da pessoa idosa, considerando o envelhecimento populacional, estratégias como essa apresentam-se como tecnologias alternativas na promoção de um cuidado qualificado à família de pessoas idosas, no âmbito dos cuidados primários, potencialmente podendo ser reproduzida no cenário da ABS/ESF.

Ainda, a abordagem familiar tem sido apresentada como intervenção relevante a ser implementada por famílias de difícil manejo junto às equipes de saúde, tanto pelo presente resultado quanto por estudos anteriores. Haja vista que a adoção do Modelo Calgary é indicada como benéfica à promoção da interação com as famílias e ao melhor planejamento dos cuidados.

Torna-se crucial implementar estratégias para a transferência das evidências identificadas neste estudo de caso à equipe de saúde da família de referência desta unidade familiar, para com isso resguardar o fornecimento de suporte emocional para apoiar as mudanças sugeridas na funcionalidade familiar.

Os resultados apresentados contribuem para o incremento de produções científicas que discutam a formação interprofissional de forma a dialogar com a complexidade do trabalho na ABS/ESF. Ainda, é necessário implementar estratégias para a transferência das evidências identificadas neste estudo de caso à equipe de saúde da família de referência desta unidade familiar.

Fica como sugestão a necessidade do empreendimento de pesquisas futuras, que avaliem o impacto dessa intervenção junto à unidade familiar estudada. E, como a família analisada tem se organizado, e seus arranjos internos junto ao contexto socioterritorial para a sustentação das mudanças propostas no projeto de intervenção.

\section{REFERÊNCIAS}

1. Conselho Nacional de Saúde (Brasil). Documento orientador de apoio aos debates da 15a Conferência Nacional de Saúde [Internet]. Brasília, DF: CNS; 2015 [citado em 7 ago 2015]. Disponível em: http:// conselho.saude.gov.br/web_15cns/docs/05mai 15_Documento_Orientador_15CNS.pdf

2. Silva LA, Casotti CA, Chaves SCL. A produção científica brasileira sobre a Estratégia Saúde da Família e a mudança no modelo de atenção. Ciên Saúde Colet. [Internet]. 2013 [citado em 11 maio 2018]; 18(1):221-32. DOI: 
http://dx.doi.org/10.1590/S1413-

81232013000100023

3. Santos DS, Mishima SM, Merhy EE. Processo de trabalho na Estratégia Saúde da Família: potencialidades da subjetividade do cuidado para a reconfiguração do modelo de atenção. Ciênc Saúde Colet. [Internet]. 2018 [citado em 11 maio 2018]; 23(3):861-70. DOI: http://dx.doi.org/10.1590/1413-

81232018233.03102016

4. Ministério da Saúde (Br). Portaria no 2.436, de 21 de setembro de 2017. Aprova a Política Nacional de Atenção Básica, estabelecendo a revisão de diretrizes para a organização da Atenção Básica [Internet]. D.O.U., Brasília, 22 set 2017 [citado em 10 abr 2018]. 183(seção1):68. Disponível em: http://pesquisa.in.gov.br/imprensa/jsp/visuali $\mathrm{za} /$ index.jsp?jornal=1\&data=22/09/2017\&pag ina $=68$

5. Silva MCLSR, Silva L, Bousso RS. A abordagem à família na Estratégia Saúde da Família: uma revisão integrativa da literatura. Rev Esc Enferm USP. [Internet]. 2011 [citado em 11 maio 2018]; 45(5):1250-5. DOI: http://dx.doi.org/10.1590/S0080-

62342011000500031

6. Trad LAB. Família contemporânea e saúde: significados, práticas e políticas públicas. Rio de Janeiro: Fiocruz; 2010.

7. Pareja JMD, Guerra FF, Vieira SR, Teixeira KMD. A produção do espaço e sua relação no processo de saúde - doença familiar. Saúde Soc. [Internet]. 2016 [citado em 11 maio 2018]; 25(1):133-44.

http://dx.doi.org/10.1590/S0104-

12902016152797

8. Yin RK. Estudo de caso: planejamento e métodos. Porto Alegre: Bookman; 2015.

9. Wright LM. Enfermeiras e famílias: um guia para avaliação e intervenção na família. São Paulo: Rocca; 2008.

10. Ayres JRC. Sujeito, intersubjetividade e práticas de saúde. Ciênc Saúde Colet. [Internet]. 2011 [citado em 11 maio 2018]; 6(7):63-72. DOI: $\quad$ http://dx.doi.org/10.1590/S141381232001000100005

11. Cecilio HPM, Santos KS, Marcon SS. Modelo Calgary de avaliação da família: experiência em um projeto de extensão. Cogitare Enferm. [Internet]. 2014 [citado em 11 maio 2018]; 19(3):536-44. Disponível em:
https://revistas.ufpr.br/cogitare/article/viewF ile/32729/23239

12. Santos JAD, Cunha ND, Brino SMS, Brsail CHG. Ferramenta de abordagem familiar na atenção básica: um relato de caso. J Health Sci Inst. [Internet]. 2016 [citado em 11 maio 2018]; 34(4):249-52. Disponível em: https://www.unip.br/presencial/comunicacao /publicacoes/ics/edicoes/2016/04_outdez/V34_n4_2016_p249a252.pdf

13. Alves AP, Lima CMS, Rocha WNF, Borges CFN, Silva DP, Brasil CHG, et al. Ferramentas de abordagem familiar na Estratégia Saúde da Família: relato de caso da Equipe Vila Greyce em Montes Claros, Minas Gerais, Brasil. EFDeportes.com. [Internet]. 2015 [citado em 11 maio 2018]; 19(202):1-8. Disponível em: http://www.efdeportes.com/efd202/abordage m-familiar-na-estrategia-saude.htm

14. Santos AL, Cecilio HPM, Teston EF, Marcon SS. Conhecendo a funcionalidade familiar sob a ótica do doente crônico. Texto \& Contexto Enferm. [Internet]. 2012 [citado em 11 maio 2018]; 21(4):879-86. DOI: http://dx.doi.org/10.1590/S0104-

07072012000400019

15. Santos LG, Cruz AC, Mekitarian FFP, Angelo M. Family interview guide: strategy to develop skills in novice nurses. Rev Bras Enferm. [Internet]. 2017 [citado em 11 maio 2018]; 70(6):1129-36.

DOI: http://dx.doi.org/10.1590/0034-7167-20160072

16. Santos A, Oliveira J, Oliveira B, Medeiros S. Quando a família é a principal doença. Rev Port Med Geral Fam. [Internet]. 2013 [citado em 11 maio 2018]; 29:120-5. Disponível em: http://www.scielo.mec.pt/pdf/rpmgf/v29n2/v 29n2a08.pdf

17. Santos JAD, Cunha ND, Brito SMS, Brasil CHG. Ferramenta de abordagem familiar na atenção básica: um relato de caso. J Health Sci Inst. [Internet]. 2016 [citado em 11 maio 2018]; 34(4):249-52. Disponível em: https://www.unip.br/presencial/comunicacao /publicacoes/ics/edicoes/2016/04_outdez/V34_n4_2016_p249a252.pdf

18. Duhamel F, Dupuis F, Turcotte A, Martinez AM, Goudreau J. Integrating the Illness Beliefs Model in clinical practice: a Family Systems Nursing knowledge utilization model. J Fam Nurs. [Internet]. 2015 [citado em 15 out 2016]; 
21(2):322-48.

DOI: https://doi.org/10.1177/1074840715579404

19. Angelo M, Cruz AC. Autoeficácia do enfermeiro para o relacionamento com a família. Rev Ref. 2015; 3(IV):151-5.

20. Campos ACV, Rezende GP, Ferreira EF, Vargas AMD, Gonçalves LHT. Funcionalidade familiar de idosos brasileiros residentes em comunidade. Acta Paul Enferm. [Internet]. 2017 [citado em 12 jul 2018]; 30(4):358-67. DOI: http://dx.doi.org/10.1590/19820194201700053

21. Bolina AF, Tavares DMS. Living arrangements of the elderly and the sociodemographic and health determinants: a longitudinal study. Rev Latinoam Enferm. [Internet]. 2016 [citado em 22 maio 2018]; 24:e2737. http://dx.doi.org/10.1590/15188345.0668.2737

22. Santos SC, Tonhom SFR, Komatsu RS. Saúde do idoso: reflexões acerca da integralidade do cuidado. Rev Bras Promoç Saúde [Internet]. 2016 [citado em 12 jul 2018]; 29(Supl):118-27. DOI:

http://dx.doi.org/10.5020/18061230.2016.su p.p118
23. Rocha EN, Lucena AF. Projeto Terapêutico Singular e Processo de Enfermagem em uma perspectiva de cuidado interdisciplinar. Rev Gaúch Enferm. [Internet]. 2018 [citado em 12 jul 2018]; 39:e2017-0057. DOI: http://dx.doi.org/10.1590/1983-

1447.2018.2017-0057

24. Jorge MSB, Diniz AM, Lima LL, Penha JC. Apoio matricial, projeto terapêutico singular e produção do cuidado em saúde mental. Texto \& Contexto Enferm. [Internet]. 2015 [citado em 12 jul 2018]; 24(1):112-20. DOI: http://dx.doi.org/10.1590/0104-

07072015002430013

CONTRIBUIÇõES
Ana Luísa Nunes Marques e Fernanda
Carolina Camargo contribuíram para
concepção e redação. Joyce Mara Gabriel
Duarte atuou no delineamento. Francielle
Thaisa Morais Martins e Hayanny Pires
Netto Guimarães participaram na revisão
crítica. Luana Rodrigues Rosseto Felipe,
Matheus Marques e Marques, Simone
Almeida dos Santos e Ana Jecely Alves
Pereira Lima atuaram na análise e
interpretação dos dados.

\footnotetext{
Como citar este artigo (Vancouver)

Marques ALN, Camargo FC, Duarte JMG, Lima AJAP, Martins FTM, Guimarães HPN, et al. Abordagem familiar e projeto terapêutico singular na estratégia saúde da família: estudo de caso com idosos. REFACS [Internet]. 2019 [citado em inserir dia, mês e ano de acesso]; 7(1):70-81. Disponível em: inserir link de acesso. DOI: inserir link do DOI.

\section{Como citar este artigo (ABNT)}

MARQUES, A. L. N. et al. Abordagem familiar e projeto terapêutico singular na estratégia saúde da família: estudo de caso com idosos. REFACS, Uberaba, MG, v. 7, n. 1, p. 70-81, 2019. Disponível em: $<$ inserir link de acesso >. Acesso em: inserir dia, mês e ano de acesso. DOI: inserir link do DOI.

\section{Como citar este artigo (APA)}

Marques, A.L.N., Camargo, F.C., Duarte, J.M.G., Lima, A.J.P.A., Martins, F.T.M., Guimarães, H.P.N., .. Santos, S.A. (2019). Abordagem familiar e projeto terapêutico singular na estratégia saúde da família: estudo de caso com idosos. REFACS, 7(1), 70-81. Recuperado em: inserir dia, mês e ano de acesso de inserir link de acesso. DOI: inserir link do DOI.
} 